\title{
CÂNCER DE MAMA: DO DIAGNÓSTICO A AUTO ACEITAÇÃO DA PACIENTE MASTECTOMIZADA
}

\author{
Tays Samuel Serra ${ }^{1}$ \\ Thamiris Bevilaqua de Andrade ${ }^{2}$ \\ Michelle Messias Tinoco Reis ${ }^{3}$
}

\begin{abstract}
RESUMO: O câncer de mama afeta grande parte das mulheres no Brasil, e com isso, acaba sendo o que mais gera medo as pacientes afetadas pelo mesmo. A mulher mastectomizada enfrenta a difícil tarefa de conviver com a amputação da mama, lidando assim com vários fatores que afetam suas vidas, como alterações na sexualidade, ansiedade, baixa autoestima, etc. $\mathrm{O}$ estudo em questão busca identificar quais os efeitos que a mastectomia causa em mulheres portadoras de câncer de mama, e analisar o enfretamento da mulher diante deste processo. Neste estudo, a opção foi por uma revisão bibliográfica tipo integrativa com 7 artigos publicados a partir de 2017. Para isto, priorizamos as publicações das plataformas de busca bibliotecas virtuais: biblioteca virtual SciELO - Scientifi c Electronic Library Online e google acadêmico. Foram identificados que os principais efeitos que a mastectomia causa nas mulheres são: perda da feminilidade com comprometimento da sexualidade, desfiguramento, atração sexual e perda do parceiro, baixa autoestima, além da possível morte dos papéis sociais. Nesse sentido este estudo contribui para impulsionar mudanças, transformações e inovações, tanto em nível pessoal, como profissional e institucional na assistência a essas mulheres.
\end{abstract}

Palavras-chave: Câncer de mama. Mastectomia. Enfretamento.

ABSTRACT: Breast cancer affects a large number of women in Brazil, and with that, it ends up being what most causes fear in patients affected by it. Mastectomized women face the difficult task of living with breast amputation, thus dealing with several factors that affect their lives, such as changes in sexuality, anxiety, low self-esteem, etc. The study in question seeks to identify the effects that mastectomy causes in women with breast cancer, and to analyze the woman's coping with this process. In this study, the option was for an integrative bibliographic review with 7 articles published from 2017 onwards. For this, we prioritized publications from virtual libraries search platforms: SciELO virtual library - Scientifi c Electronic Library Online and academic google. It was identified that the main effects that mastectomy causes in women are: loss of femininity with compromised sexuality, disfigurement, sexual attraction and loss of a partner, low selfesteem, in addition to the possible death of social roles. In this sense, this study

\footnotetext{
I Graduanda de Enfermagem pela Uniredentor. E-mail: taysserra82@gmail.com

${ }^{2}$ Graduanda de Enfermagem pela Uniredentor. E-mail: thamiris.bevilaquaa@hotmail

3 Docente de Enfermagem da Uniredentor. E-mai: michelletinocoreis@hotmail.com
} 
contributes to drive changes, transformations and innovations, both at a personal, professional and institutional level in the assistance to these women.

Keywords: Breast cancer. Mastectomy. coping.

\section{INTRODUÇÃO}

Câncer é um termo que engloba mais de roo diferentes tipos de doenças malignas que mantém uma característica em comum: crescimento desordenado de células em algum órgão do corpo, e se nada for feito, podem causar tanto um crescimento excessivo no local, quanto se espalharem para outros órgãos. Essas células se dividem rapidamente, se tornando muito agressivas e descontroladas determinando assim a formação de tumores. (INCA, 2009).

O câncer da mama é o tipo de câncer que mais afeta as mulheres no Brasil, tirando o câncer de pele não melanoma. Esse tipo de câncer tem sido o mais temido entre as mulheres, em razão à sua alta frequência e efeitos psicológicos, como: alterações da sexualidade e da imagem corporal, medo de recidivas, ansiedade, dor e baixa autoestima. Seus principais sinais e sintomas são nódulo na mama e/ou axila, dor mamária e alterações da pele que recobre a mama, como abaulamentos ou retrações com aspecto semelhante à casca de laranja. (SILVA; RIUL, 20II).

Os principais fatores de risco para o aparecimento de câncer de mama estão relacionados com idade avançada, características reprodutivas, história familiar e pessoal, hábitos de vida e influências ambientais. Quanto antes o câncer for detectado melhores são as chances de tratamento, tendo como meios mais eficazes para a deteç̧ão precoce o exame clínico de mamas (ECM) e a mamografia, pois o autoexame das mamas (AEM) detecta a doença geralmente já em estádio avançado. (SARTORI; BASSO, 2019).

O autoexame das mamas surgiu nos Estados Unidos como método para reduzir o diagnóstico de tumores de mama em estágio avançada. Porém no final da década de 1990, alguns ensaios clínicos apresentaram que o autoexame não reduzia a mortalidade pelo câncer de mama. Assim vários países começaram a admitir uma nova estratégia de conscientizar as pessoas sobre a saúde da mama, destacando sobre a importância de um diagnóstico precoce e orientando a população feminina sobre as mudanças habituais das 
mamas em diferentes momentos do ciclo de vida e os principais sinais suspeitos de câncer de mama. (MIGOWSKI et al, 2018).

Com o diagnóstico da doença, o médico deve discutir com a paciente sobre suas opções de tratamento. Existem diversos tipos de tratamentos para o câncer de mama que dependem do tipo e do estágio da doença. Entre os tratamentos temos: Tratamentos sistêmicos que se refere ao uso de medicamentos que podem ser administrados por via oral ou diretamente na corrente sanguínea para atingir as células cancerígenas em qualquer parte do corpo, como a quimioterapia, hormonioterapia, terapia alvo, imunoterapia, que serão definidos dependendo do tipo do câncer. (SOUZA, et al, 2008).

Já os tratamentos locais visam tratar um tumor local, sem afetar o resto do corpo. Os tipos de terapia local utilizados para o câncer de mama incluem: A Radioterapia que é geralmente indicado para pacientes que retiraram o tumor através de cirurgia. Utiliza-se radiação ionizante no local onde estava o tumor para eliminar ou impedir a propagação das células que formam o câncer; e a Cirurgia que consiste na remoção do tumor primário e, eventualmente os linfonodos axilares, quando é necessário. (TEXEIRA; NETO, 2020).

A mastectomia é a retirada total da mama que possui o câncer e pode ser parcial, quando som uma parte do tecido é removido, total, quando a mama é retirada por completo ou, radical, quando são retirados músculos e tecidos próximos. (PEREIRA, et al, 2019).

Pacientes oncológicos demonstram um preocupante quadro de baixa autoestima diante do estigma de morte que esta doença carrega. A mastectomia é uma intervenção que causa um impacto profundo na saúde mental da mulher em razão de a mama também ser um órgão sexual e, ao mesmo tempo, integrando a imagem da constituição de ser mulher, comprometendo assim a imagem corporal de si mesma e para os demais, influenciando automaticamente, em sua autoestima. (SANTOS, et al, 2019).

O enfermeiro é uma figura muito importante na equipe multiprofissional, pois eles mantem, uma comunicação terapêutica que favorece um cuidado que atende as expectativas e necessidades da mulher mastectomizada. Por tanto, o enfermeiro responsável pelo cuidado da mulher mastectomizada, precisa planejar e estabelecer metas para dá o melhor conforto a paciente. (SOUZA, et al, 2014). 
O presente estudo tem como justificativa, debater o tema em questão com o intuito de ressaltar para os profissionais de saúde a importância adotar métodos que conforte a paciente mastectomizadas, visto que essa intervenção causa um impacto profundo na saúde mental da mulher. Objetivando analisar o enfretamento da mulher diante do processo de mastectomia.

\section{MATERIAIS E MÉTODOS}

O presente estudo é uma revisão integrativa, que tem como principal característica uma ampla abordagem de metodologias referentes às revisões bibliográficas em diferentes rotas de desenvolvimento, propiciando uma análise completa do objeto de pesquisa (SOUZA et al., 2010).

A coleta de informações foi realizada a partir da base de dados virtual SciELO Scientifi c Electronic Library Online e google acadêmico, sempre utilizando as palavraschave "câncer de mama", "diagnóstico" e "mastectomia".

A escolha dos artigos foi realizada mediante a leitura dos resumos, a fim de confirmar a temática proposta. Tais resumos demonstravam pesquisa de campo e referências bibliográficas que abordavam o câncer de mama e como ele pode atuar dentro deste contexto proposto por tal estudo. Foram utilizados como métodos de exclusão artigos que não eram pertinentes ao objetivo da pesquisa e que não atendessem a questão norteadora.

\section{RESULTADOS}

A partir da análise realizada, optou-se por produzir um fluxograma que possibilite apresentar todos os artigos escolhidos de maneira sintética para uma visão mais ampla. A FIGURA I apresenta uma análise mais geral dos artigos, desde a identificação até a inclusão. 
FIGURA r: FLUXOGRAMA DO PROCESSO DE SELEÇÃO DOS ARTIGOS

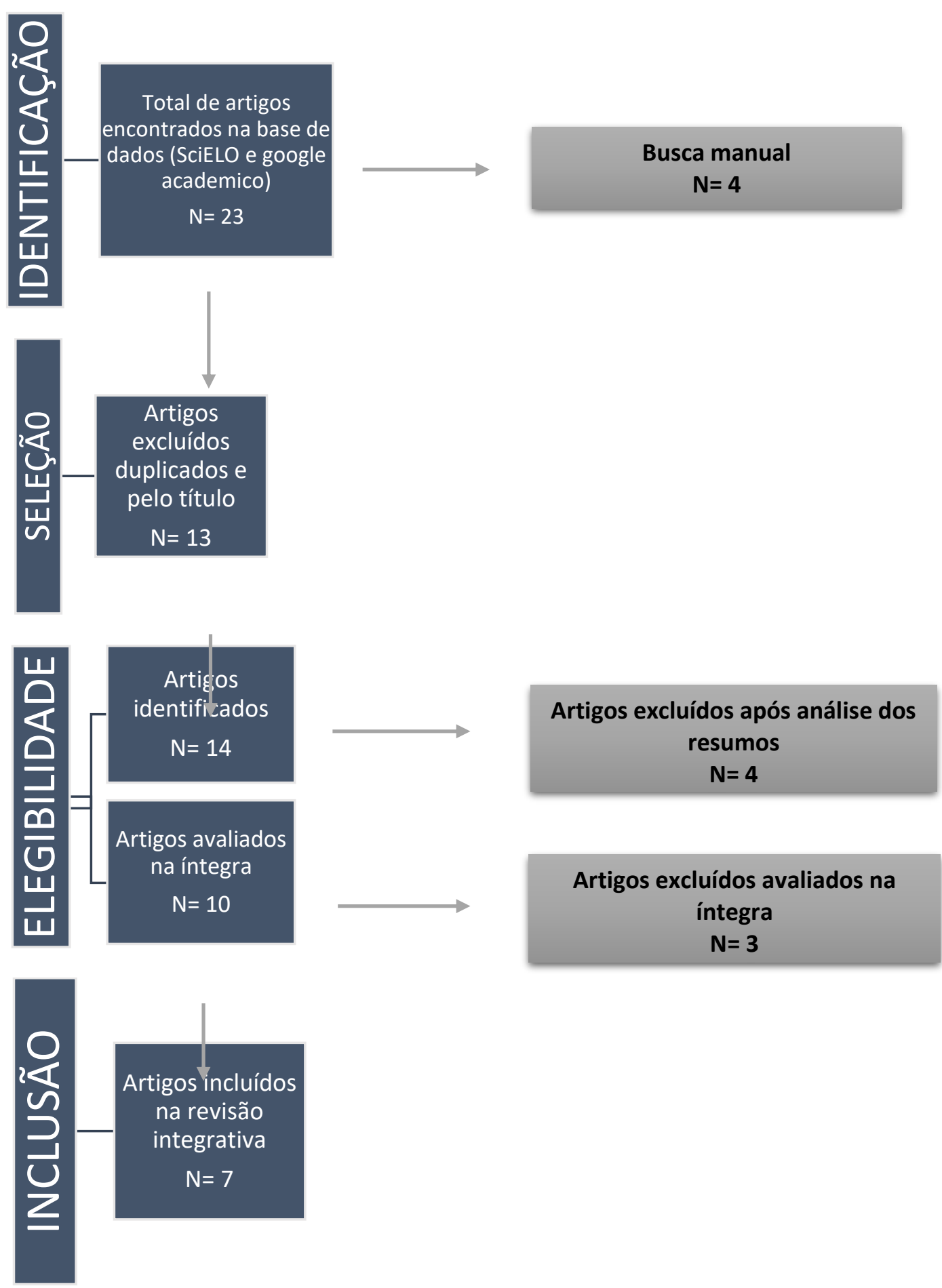


DOS ESTUDOS INCLUÍDOS NA PESQUISA.

\begin{tabular}{|c|c|c|c|c|c|}
\hline Autores & Título & Objetivos & Métodos & Resultados & $\begin{array}{c}\text { Quais efeitos a } \\
\text { mastectomia } \\
\text { causa em } \\
\text { mulheres } \\
\text { portadoras de } \\
\text { câncer de } \\
\text { mama? }\end{array}$ \\
\hline $\begin{array}{l}\text { Fireman } \\
\text { et al, } \\
(2018) \text {. }\end{array}$ & $\begin{array}{l}\text { Percepção das } \\
\text { Mulheres sobre } \\
\text { sua } \\
\text { Funcionalidade e } \\
\text { Qualidade de } \\
\text { Vida após } \\
\text { Mastectomia. }\end{array}$ & $\begin{array}{l}\text { Compreender e } \\
\text { descrever a } \\
\text { percepção das } \\
\text { pacientes sobre o } \\
\text { impacto do } \\
\text { tratamento } \\
\text { oncológico e a } \\
\text { contribuição da } \\
\text { fisioterapia na } \\
\text { recuperação da } \\
\text { sua qualidade de } \\
\text { vida e } \\
\text { funcionalidade. }\end{array}$ & $\begin{array}{l}\text { Estudo } \\
\text { qualitativo }\end{array}$ & $\begin{array}{l}\text { Após o } \\
\text { tratamento, as } \\
\text { pacientes } \\
\text { relataram } \\
\text { melhora da } \\
\text { capacidade } \\
\text { funcional, } \\
\text { emocional e } \\
\text { autoestima, } \\
\text { possibilitando } \\
\text { sua reinserção } \\
\text { social e retorno } \\
\text { às atividades de } \\
\text { vida diária. }\end{array}$ & $\begin{array}{l}\text { O estuda } \\
\text { mostra que } \\
\text { algumas } \\
\text { mulheres } \\
\text { relataram } \\
\text { alterações de } \\
\text { humor após a } \\
\text { mastectomia, } \\
\text { outras } \\
\text { relataram } \\
\text { distúrbios do } \\
\text { sono, } \\
\text { insegurança e } \\
\text { negação. }\end{array}$ \\
\hline $\begin{array}{l}\text { Pereira } \\
\text { et al, } \\
(2019)\end{array}$ & $\begin{array}{l}\text { Mastectomia e o } \\
\text { sistema de } \\
\text { enfrentamento } \\
\text { feminino: } \\
\text { nuances do apoio } \\
\text { social e familiar. }\end{array}$ & $\begin{array}{l}\text { Descrever as } \\
\text { percepções de } \\
\text { mulheres que } \\
\text { realizaram } \\
\text { mastectomia } \\
\text { acerca do grupo } \\
\text { de apoio e do } \\
\text { suporte. }\end{array}$ & $\begin{array}{l}\text { Estudo } \\
\text { qualitativo } \\
\text { de natureza } \\
\text { descritiva. }\end{array}$ & $\begin{array}{l}\text { Constatou-se que } \\
\text { o grupo de apoio } \\
\text { foi de grande } \\
\text { ajuda para uma } \\
\text { melhor aceitação } \\
\text { da doença, como } \\
\text { também auxiliou } \\
\text { em uma grande } \\
\text { troca de } \\
\text { experiências e } \\
\text { aprendizados } \\
\text { pelas envolvidas. } \\
\text { Boa parte das } \\
\text { mulheres elencou } \\
\text { a família como } \\
\text { de extrema } \\
\text { importância em } \\
\text { todo processo. } \\
\text { Percebeu-se uma } \\
\text { influência }\end{array}$ & $\begin{array}{l}\text { No estudo em } \\
\text { tela, observou- } \\
\text { se também que } \\
\text { algumas } \\
\text { mulheres } \\
\text { sofreram } \\
\text { preconceito e } \\
\text { rejeição de } \\
\text { pessoas de } \\
\text { convívio } \\
\text { próximo. }\end{array}$ \\
\hline
\end{tabular}




\begin{tabular}{|c|c|c|c|c|c|}
\hline & & & & $\begin{array}{l}\text { negativa nas } \\
\text { relações } \\
\text { matrimoniais. }\end{array}$ & \\
\hline $\begin{array}{l}\text { Lima et } \\
\text { al, } \\
(2018) .\end{array}$ & $\begin{array}{l}\text { Sentimentos } \\
\text { vivenciados pelas } \\
\text { mulheres } \\
\text { mastectomizadas }\end{array}$ & $\begin{array}{l}\text { Desvelar os } \\
\text { sentimentos das } \\
\text { mulheres } \\
\text { mastectomizadas } \\
\text {. }\end{array}$ & $\begin{array}{l}\text { Estudo } \\
\text { quantiquali } \\
\text { tativo, } \\
\text { descritivo e } \\
\text { exploratóri } \\
\text { o. }\end{array}$ & $\begin{array}{l}\text { Em relação aos } \\
\text { aspectos clínicos, } \\
\text { a maioria } \\
\text { realizou } \\
\text { mastectomia } \\
\text { total e a metade a } \\
\text { reconstrução } \\
\text { mamária. A } \\
\text { perda da mama } \\
\text { acarretou em } \\
\text { prejuízos físicos, } \\
\text { porém, a forma } \\
\text { como cada uma } \\
\text { passou pelo } \\
\text { processo de } \\
\text { adoecimento e } \\
\text { tratamento } \\
\text { estava associada } \\
\text { aos significados } \\
\text { que atribuíram a } \\
\text { doença. }\end{array}$ & $\begin{array}{l}\text { A raiva, o } \\
\text { desespero, a } \\
\text { tristeza, } \\
\text { inquietação, } \\
\text { ansiedade, } \\
\text { angústia, medo } \\
\text { e luto são } \\
\text { sentimentos } \\
\text { comuns } \\
\text { durante esse } \\
\text { período, } \\
\text { embora cada } \\
\text { paciente } \\
\text { vivencia de } \\
\text { forma } \\
\text { particular cada } \\
\text { etapa. }\end{array}$ \\
\hline $\begin{array}{l}\text { Reis et } \\
\text { al, } \\
\text { (2019). }\end{array}$ & $\begin{array}{l}\text { Enfrentamento } \\
\text { de mulheres que } \\
\text { vivenciaram o } \\
\text { câncer de mama. }\end{array}$ & $\begin{array}{l}\text { Conhecer as } \\
\text { mulheres que } \\
\text { recebem o } \\
\text { diagnóstico do } \\
\text { câncer de mama. }\end{array}$ & $\begin{array}{l}\text { Estudo } \\
\text { qualitativo. }\end{array}$ & $\begin{array}{l}\text { A metodologia } \\
\text { permitiu a } \\
\text { discussão em } \\
\text { três categorias } \\
\text { para debate da } \\
\text { teoria, sendo elas: } \\
\text { recebendo a } \\
\text { notícia do } \\
\text { diagnóstico e da } \\
\text { necessidade dos } \\
\text { tratamentos; } \\
\text { adaptação } \\
\text { ao tratamento; } \\
\text { experiências } \\
\text { anteriores frente } \\
\text { à doença. } \\
\text { Verificamos que } \\
\text { o enfrentamento } \\
\text { surgiu, em todas } \\
\text { as etapas da } \\
\text { doença, como }\end{array}$ & $\begin{array}{l}\text { No presente } \\
\text { mostrou que } \\
\text { quando a } \\
\text { mulher recebe } \\
\text { a notícia que a } \\
\text { mastectomia } \\
\text { será uma } \\
\text { opção para o } \\
\text { tratamento, } \\
\text { elas } \\
\text { desenvolvem } \\
\text { crises de } \\
\text { instabilidade } \\
\text { emocional, } \\
\text { marcadas por } \\
\text { frustrações, } \\
\text { conflitos, } \\
\text { medose } \\
\text { insegurança. }\end{array}$ \\
\hline
\end{tabular}




\begin{tabular}{|c|c|c|c|c|c|}
\hline & & & & $\begin{array}{l}\text { forma de superar } \\
\text { os tratamentos e } \\
\text { os aspectos } \\
\text { sociais que o } \\
\text { câncer trás. }\end{array}$ & \\
\hline $\begin{array}{l}\text { Batista } \\
\text { et al, } \\
(2017) \text {. }\end{array}$ & $\begin{array}{l}\text { Sentimentos de } \\
\text { mulheres com } \\
\text { câncer de mama } \\
\text { após } \\
\text { mastectomia. }\end{array}$ & $\begin{array}{l}\text { Conhecer os } \\
\text { sentimentos de } \\
\text { mulheres com } \\
\text { câncer de mama } \\
\text { após } \\
\text { mastectomia. }\end{array}$ & $\begin{array}{l}\text { Estudo } \\
\text { descritivo, } \\
\text { com } \\
\text { abordagem } \\
\text { qualitativa. }\end{array}$ & $\begin{array}{l}\text { Foram definidas } \\
\text { duas categorias }<< \\
\text { Vivenciando o } \\
\text { diagnóstico de } \\
\text { câncer de mama: } \\
\text { saberes e } \\
\text { resiliência } \\
\text { feminina } \gg \text { e }<< \\
\text { Desvelando os } \\
\text { sentimentos de } \\
\text { mulheres perante } \\
\text { a mastectomia }>\text {. }\end{array}$ & $\begin{array}{l}\text { Ao perder a } \\
\text { mama, a } \\
\text { mulher } \\
\text { experimenta } \\
\text { sentimento de } \\
\text { tristeza, } \\
\text { estranheza e } \\
\text { preocupação } \\
\text { pelo } \\
\text { comprometim } \\
\text { ento da } \\
\text { autoimagem. }\end{array}$ \\
\hline $\begin{array}{l}\text { Martins } \\
\text { et al, } \\
(2020) \text {. }\end{array}$ & $\begin{array}{l}\text { Sexualidade de } \\
\text { mulheres } \\
\text { submetidas à } \\
\text { mastectomia: } \\
\text { identificação das } \\
\text { fases afetadas no } \\
\text { ciclo da resposta } \\
\text { sexual. }\end{array}$ & $\begin{array}{l}\text { Analisar a } \\
\text { sexualidade das } \\
\text { mulheres } \\
\text { mastectomizadas } \\
\text {, identificando } \\
\text { quais as fases do } \\
\text { ciclo da resposta } \\
\text { sexual são } \\
\text { afetadas e quais } \\
\text { as disfunções } \\
\text { desenvolvidas. }\end{array}$ & $\begin{array}{l}\text { Pesquisa } \\
\text { descritiva } \\
\text { de cunho } \\
\text { quantitativ } \\
\text { o. }\end{array}$ & $\begin{array}{l}\text { O desempenho } \\
\text { sexual da } \\
\text { população } \\
\text { estudada } \\
\text { apresentou-se } \\
\text { heterogêneo, } \\
\text { onde 50\% } \\
\text { apresentou } \\
\text { padrão sexual } \\
\text { satisfatório e 50\% } \\
\text { algum tipo de } \\
\text { comprometiment } \\
\text { o na sexualidade, } \\
\text { e dentro deste } \\
\text { grupo, incluem- } \\
\text { se as casadas, } \\
\text { com menos de } 49 \\
\text { anos e com grau } \\
\text { de instrução de } \\
\text { nível } \\
\text { fundamental. }\end{array}$ & $\begin{array}{l}\text { Neste estudo, } \\
\text { em geral, as } \\
\text { mulheres } \\
\text { apresentaram } \\
\text { disfunção } \\
\text { sexual. A } \\
\text { alteração } \\
\text { sexual mais } \\
\text { frequente é na } \\
\text { fase do desejo, } \\
\text { caracterizando } \\
\text { desejo } \\
\text { hipoativo, o } \\
\text { que } \\
\text { compromete a } \\
\text { fase seguinte, a } \\
\text { excitação, } \\
\text { justamente } \\
\text { devido à } \\
\text { correlação } \\
\text { entre elas. }\end{array}$ \\
\hline $\begin{array}{l}\text { Oliveira } \\
\text { et al, } \\
\text { (2019). }\end{array}$ & $\begin{array}{l}\text { Câncer de mama } \\
\text { e imagem } \\
\text { corporal: impacto } \\
\text { dos tratamentos } \\
\text { no olhar de } \\
\text { mulheres }\end{array}$ & $\begin{array}{l}\text { Avaliar a } \\
\text { percepção da } \\
\text { imagem corporal } \\
\text { de mulheres } \\
\text { mastectomizadas } \\
\text {, com ou sem }\end{array}$ & $\begin{array}{l}\text { Trata-se de } \\
\text { um estudo } \\
\text { descritivo, } \\
\text { transversal, } \\
\text { com } \\
\text { abordagem }\end{array}$ & $\begin{array}{l}\text { Cuidado com a } \\
\text { saúde das } \\
\text { mulheres } \\
\text { acometidas pela } \\
\text { doença demanda } \\
\text { assistência }\end{array}$ & $\begin{array}{l}\text { Neste estudo } \\
\text { algumas } \\
\text { mulheres } \\
\text { relataram } \\
\text { receio que } \\
\text { surge é o da }\end{array}$ \\
\hline
\end{tabular}




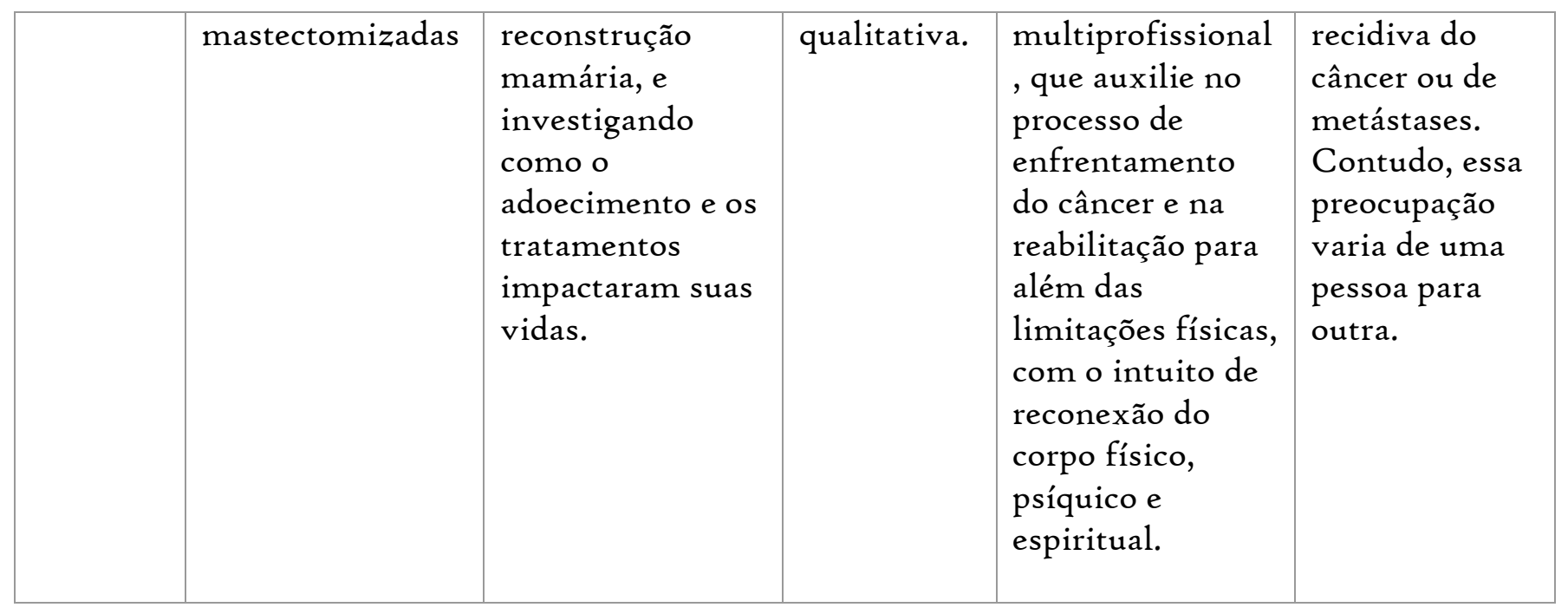

\section{DISCUSSÃO}

Segundo Lima et al, (2018), a maneira que o corpo da mulher é representado desempenha uma parte importante na construção da autoimagem, e a forma como a mama vem sendo notada progressivamente pela sociedade, influencia na formação da imagem corporal das mulheres.

Reis et al, (2019) relata que as mulheres entrevistadas em sua pesquisa declararam que após o diagnóstico do câncer se sentiram fragilizadas e impotentes. Expressaram ainda sentimento de medo diante da possibilidade de morte, visto que foi dessa maneira que o câncer se apresentou a elas.

Fireman et al, (2018) evidenciou por meio de suas entrevistas que todas as mulheres relataram dificuldades em aceitar a perda da mama, demonstrando diminuição de sua autoestima e vergonha de sua própria imagem. Descreveram como traumático o momento em que se viram no espelho pela primeira vez após a mastectomia, impactando assim negativamente em suas relações afetivas, em particular no que se refere à sexualidade.

Em seu estudo Martins et al, (2020) entrevistou 70 mulheres, e no que se refere as disfunções sexuais, $50 \%$ a $64 \%$ das mulheres com câncer de mama demonstraram dificuldade de excitação, desejo e lubrificação. Relataram ainda, ausência de apoio e compreensão de seu companheiro, na fase do processo de autoaceitação pós mastectomia. 
Para Oliveira et al, (2019) a mastectomia carrega uma representação muito expressiva no tratamento do câncer de mama, e cada mulher vivência essa doença de maneira individual. Em sua pesquisa o autor afirma que 4 das io mulheres entrevistadas relataram sentir medo em relação a cirurgia, e 6 já relataram não temer a cirurgia, pois viam a retirada da mama como solução do problema para sua sobrevivência.

Pereira et al, (2019) chegou à conclusão que grupos de apoios são de grande ajuda para as mulheres aceitarem melhor a doença, pois auxilia em troca de experiências e aprendizados. E no que refere-se ao apoio familiar e social, o autor relata que grande parte das mulheres citaram a família como fator fundamental diante de todo processo do enfrentamento da doença, no entanto percebeu-se influência negativa nas relações conjugais.

Batista et al, (2017) demonstrou em seu estudo que os sentimentos acometidos a mulheres portadoras do câncer de mama inicialmente são de desespero e surpresa diante da doença, e ao se depararem com a mastectomia, como tratamento, surgem a negação, tristeza, ansiedade, depressão e, enfim, a aceitação.

Batista et al, (2017) ainda declara, que nesse sentido, se faz necessário um atendimento integral e humanizado dos profissionais de saúde, no que tange à assistência de qualidade a essas mulheres, buscando incentivar a criação de meios que proporcionem uma atenção de qualidade na trajetória da reconstrução de suas vidas.

\section{CONSIDERAÇÃO FINAL}

A mulher com câncer de mama, quando recebe a notícia que a mastectomia será uma forma de tratamento, ela se depara com um realidade difícil e inúmeros sentimentos conflitantes acomete esse contexto.

Percebeu -se que grupos de apoios, apoio familiar e social se faz fundamental durante todo enfrentamento da doença, no entanto no que refere-se a relações conjugais notou-se influência negativa.

Concluímos que este estudo permitiu-se refletir sobre o enfrentamento das mulheres que passaram por uma mastectomia. Neste sentido, é importante frisar que pesquisa nessa temática são extremamente necessárias tanto para auxiliar na definição de 
estratégias que foquem na preparação de mulheres que serão submetidas a mastectomia, bem como o acompanhamento seguido a cirurgia, almejando uma melhora na qualidade de vida e redução do sofrimento dessas mulheres em virtude de sua autoimagem afetada.

\section{REFERÊNCIA}

INSTITUTO NACIONAL DO CÂNCER: Estimativas da incidência e mortalidade por câncerno Brasil. Ministério da Saúde: INCA, 2009. Disponível em: <https://www.google.com/url?sa=t\&source=web\&rct=j\&url=http://bvsms.saude.gov.br /bvs/publicacoes/estimativa_20Io_incidencia_cancer.pdf\&ved=2ahUKEwjGg_i6wobxAh XtrZUCHY1 QAcoQFjACegQIAxAC\&usg=AOvVaw2bVlRh5seHSpacFPoCSnRq>. Acesso em: 8 mai.2021.

SILVA, P. A; RIUL, S. S. Câncer de mama: fatores de risco e detecção precoce. Rev BrasEnferm, Brasília 2oII nov-dez; 64(6): IoI6-2I. Disponível em: <https://doi.org/10.1590/So034-71672011000600o05>. Acesso em: I8 mai. 2021.

SARTORI, A. C. N; CAROLINE S. BASSO, C. S; Câncer de mama: uma breve revisão deliteratura. Perspectiva, Erechim. v. 43, n.16ı, p. 07-13, março/2019. Disponível em:

$\langle$ https://www.google.com/url?sa=t\&source=web\&rct=j\&url=https://www.uricer.edu.br/s ite/pdfs

/perspectiva/I6I_742.pdf\&ved=2ahUKEwj5g82ZyYbxAhWJqZUCHRvBDRkQFjAAeg QIAxAC\&usg=AOvVawoCghzr-pvu-DAfH5Q42ylY>. Acesso em: I2 mai. 202I.

MIGOWSKI, A; SILVA, G. A; DIAS, M. B. K; DIZ, M. D. P. E; SANT’ANA, D. R; NADANOVSKY, P; Diretrizes para detecção precoce do câncer de mama no Brasil. II - Novas recomendações nacionais, principais evidências e controvérsias. Cad. Saúde Pública, 2018. Disponível em:< http://www.scielo.br/pdf/csp/v34n6/1678-4464csp-34-o6-e00074817.pdf $>$. Acesso em: 8 mai. 2021. 
SOUZA, V. O; GRANDO, J. P. S; FILHO, J. O; Tempo decorrido entre o diagnóstico de câncer de mama e o início do tratamento, em pacientes atendidas no Instituto de Câncer de Londrina. RBM Rev Bras Med, 2008. Disponível em:< http://bases.bireme.br/cgibin/wxislind.exe/iah/online/?IsisScript $=\mathrm{iah} / \mathrm{iah} . \mathrm{xis} \& \mathrm{src}=$ google\&base $=$ LILACS\&lang $=\mathrm{p}$ \&nextA

ction $=\operatorname{lnk} \&$ exprSearch $=485556 \&$ indexSearch $=$ ID\#: :text $=$ O\%2otempo\%2odecorrido\%2oent r e\%200,maioria\%2odos\%20casos\%20(72\%25).>. Acesso em: 3 mai. 2021.

TEIXEIRA, L. A; NETO, L. A. A. Câncer de mama no Brasil: medicina e saúde pública no século XX. Saúde Soc. São Paulo, v.29, n.3, 2020. Disponível em: 〈https://doi.org/I0.1590/So104-I2902020180753〉. Acesso em: I9 mai. 2021.

SANTOS, M. S; FREITAS, D. F. L; ANDRADE, J. S. O; SILVA, F. M. L. Implicações da

mastectomia na autoestima da mulher. Revista Eletrônica Acervo Saúde / Electronic Journal Collection Health, ISSN 2178-2091. Julho, 2019. Disponível em: 〈https://doi.org/ro.25248/reas.eII24.2019〉. Acesso em: 23 mai. 2021.

PEREIRA, A. P. V. M; SANTOS, G. R.F; FURTADO, L. F. T; MOLINA, M. A; LUZ, T. F. N;

ESTEVES, A. P. V.S. Mastectomia e mamoplastia na vida das mulheres com câncer demama. Revista Caderno de Medicina, Vol 2. $\mathrm{N}^{\circ}$ I, 2019. Disponível em: <http://www.revista.unifeso.edu.br/index.php/cadernosdemedicinaunifeso/article/view /I294>.Acesso em: 8 abr. 2021.

SOUSA, A. L. V; ANA, G. S; COSTA, Z. M. B. Análise de qualidade de vida em mulheres mastectomizadas atendidas no ambulatório do HBDF. Com. Ciência Saúde, Brasília, v. 25, n. I, p.13-24, jul. 20I4. Disponível em: <https://www.academia.edu/37919504/An\%C3\%Arlise_da_qualidade_de_vida_em_mulher es_mastectomizadas_atendidas_no_ambulat\% $\mathrm{C}_{3} \% \mathrm{~B}_{3}$ rio_do_HBDF_An\%C3\%Arlise_da_qu 
alidade_de_vida_em_mulheres_mastectomizadas_atendidas_no_ambulat\%C3\%B3rio_do_H $\mathrm{BDF}_{-}>$. Acesso em: I8 mai. 2021.

BAtista, K. A; MERCES, M. C; SANTANA, A. I. C; PINHEIRO, S. L; LUA, I; OLIVEIRA, D. S. Sentimentos de mulheres com câncer de mama após mastectomia. Rev. enferm. UFPE on line; II (7): 2788-2794, jul.2017. Disponivel em: < https://periodicos.ufpe.br/revistas/revistaenfermagem/article/view/23454/19166>. Acesso em I out. 202I.

LIMA, M. M. G; LEITE, K. N. S; CALDAS, M. L. L. S; CÉSAR, E. R. S; SOUZA, T. A; NASCIMENTO, B. B; BARBOZA, J. P; DANTAS, T. M. Sentimentos vivenciados pelas mulheres mastectomizadas. Rev. enferm. UFPE on line ; 12(5): 1216-1224, maio 2018. Disponivel em: < https://pesquisa.bvsalud.org/portal/resource/pt/biblio-980408> Acesso em 27 out. 202I.

OLIVEIRA, T. R; CORRÊAA, C. S. L; WEISS, V. F; BAQUIÃO, A. S. A; CARVALHO, L. L; GRINCENKOV, F. R. S; CARVALHO, S. M. Câncer de mama e imagem corporal: impacto dos tratamentos no olhar de mulheres mastectomizadas. Saude e pesqui. 2019.

FIREMA, K. M; MACEDO, F. O; TORRES, D. M; FERREIRA, F. O, LOU, M. B. A. Percepção das Mulheres sobre sua Funcionalidade e Qualidade de Vida após Mastectomia. Rev. Bras. Cancerol. 2018. Disponível em: 〈https://rbc.inca.gov.br/revista/index.php/revista/article/view/r98〉 Acesso em io de set. 2021.

REIS, A. P. A; PANOBIANCO, M. S; GRADIM, C. V. C. Enfrentamento de mulheres que vivenciaram o câncer de mama. Revista de Enfermagem do Centro Oeste Mineiro. 2019. Disponível em: < http://dx.doi.org/10.19175/recom.v9io.2758> Acesso em 25 de out. 2021. 
MARTINS, J. O. A; SANTOS, A. A. P; HOLANDA, J. B. L; TRINDADE,R. F. C; LIMA, L. K. P. Sexualidade de mulheres submetidas à mastectomia: identificação das fases afetadas no ciclo da resposta sexual. Rev. Pesqui. 2020

PEREIRA, T. I. M. M; SILVA ,C. R. D. V; GALIZA, D. D. F; SILVA, B. N; ALENCAR, R. M; VÉRAS, G. C. B. Mastectomia e o sistema de enfrentamento feminino: nuances do apoio social e familiar. REAID. 2019. Disponível em: 〈https://revistaenfermagematual.com/index.php/revista/article/view/152〉 Acesso em I2 de out. 202I 